\title{
KLEPTOMANIA: MANIFESTASI KLINIS DAN PILIHAN TERAPI
}

\author{
Korespondensi: blue levani@yahoo.com \\ Yelvi Levani', Aldo Dwi Prastya ${ }^{2}$, Safira Nur Ramadhani ${ }^{2}$ \\ ${ }^{1}$ Dosen Fakultas Kedokteran Universitas Muhammadiyah Surabaya \\ ${ }^{2}$ Mahasiswa Fakultas Kedokteran Universitas Muhammadiyah Surabaya
}

\begin{abstract}
Abstrak
Kleptomania (curi patologis) merupakan salah satu bentuk gangguan kejiawaan yang ditandai dengan mencuri berulang. Perilaku tersebut disertai dengan keinginan kuat yang sulit dikendalikan. Kleptomania dapat berhubungan dengan gangguan kejiwaan seperti depresi, kecanduan alcohol, gangguan kecemasan dan gangguan obsesif kompulsif. Kleptomania memiliki kesamaan gejala dengan adiksi seperti adanya tekanan yang kuat sebelum keinginan tersebut dicapai, penurunan keinginan segera sesaat setelah aksi dilakukan, adanya jeda waktu (jam, hari atau minggu) terhadap munculnya keinginan melakukan aksi pencurian berulang, serta terdapat perasaan senang setelah melakukan aksinya Kleptomania juga dapat berkaitan dengan perubahan mood. Kriteria diagnostik untuk kleptomania berdasarkan American Psychiatric Association Diagnostic and Statistical Manual of Mental Disorders diantaranya adalah prilaku mencuri barang berulang dimana penderita tidak mampu untuk mengendalikan keinginan tersebut. Barang yang dicuri biasanya tidak diperlukan oleh pasien dan bukan untuk dijual. Terdapat beberapa alat bantu untuk penegakkan diagnosis kleptomania diantaranya adalah Yale Brown Obsessive Compulsive Scale Modified for Kleptomania (K-YBOCS) dan Kleptomania Symptom Asessment Scale (K-SAS). K-YBOSC merupakan alat ukur keparahan gejala kleptomania. Untuk terapi farmakologi diantaranya Selective serotonin reuptake inbibitors (SSRI) merupakan golongan antidepresan yang bekerja dengan meningkatkan level serotonin di otak dan naltrexon merupakan terapi medikasi terhadap adiksi alcohol selain itu beberapa psikoterapi yang banyak dilakukan untuk penderita kleptomania adalah Cognitive Behavioral Therapy (CBT), psikoterapi kognitif, desensitisasi sistemik dan terapi aversi. Psikoterapi ini bertujuan untuk mengubah persepsi penderita terhadap tindakan mencuri dan mengalihkan minat ke hal lain.
\end{abstract}

Kata kunci: kleptomania, psikopatologi, adiksi

\begin{abstract}
Kleptomania (pathological stealing) is a form of mental disorder characterized by repeated stealing. This behavior is accompanied by strong desires that are difficult to control. Kleptomania can be associated with psychiatric disorders such as depression, alcoholism, anxiety disorder and obsessive compulsive disorders. Kleptomania has similarities with symptoms of addiction such as a strong pressure before the desire is achieved, a decrease in desire immediately after the action is done, there is a time lag (bours, days or weeks) to the emergence of the desire to do repeated theft, and there is a feelingof pleasure after doing. Kleptomania can also be related to mood changes. Diagnostic criteria for kleptomania based on the American Psychiatric Association's Diagnostic and Statistical Manual of Mental Disoerders include the behavior of stealing repetitive items in which the patient is unable to control these desires. Stolen items are usually not needed by patients and are not for sale. There are several tools to help diagnose keleptomania including the Yale Brown Obsessive Compulsive Scale Modified for Kleptomania (K-YBOCS) and Kleptomania Symptom Assesment Scale (K-SAS). K-YBOCS ia a measure of the severity of kleptomania symptoms. For pharmacological therapy including selective serotonin reuptake inbibitors (SSRIs) are antidepressant groups that work by increasing serotonin levels in the brain and naltrexone is a therapeutic treatment for alcohol addiction in addition to that some psycotheraphy that is mostly done for sufferers of kleptomania os Cognitive Behavioral Therapy (CBT), cognitive psychotherapy, systemic desensitization and aversion therapy. This psychotherapy aims to change the patient's perception of the act of stealing and divert interest to other things.
\end{abstract}

Keywords: Kleptomania, psychopathology, addiction 


\section{PENDAHULUAN}

Kleptomania (curi patologis) merupakan salah satu gangguan kejiwaan yang ditandai dengan perilaku mencuri berulang. Prilaku tersebut disertai dengan keinginan kuat yang tidak dapat dikendalikan. Umumnya barang yang dicuri tersebut tidak berharga dan tidak diperlukan secara pribadi oleh pelaku. Barang curian itu kemudian dibuang, diberikan kepada orang lain, dikembalikan secara diam-diam atau dikumpulkan. Sebelum melakukan aksi mencuri, pelaku merasakan peningkatan ketegangan dan merasakan kepuasan setelahnya. Dalam Pedoman Penggolongan dan Diagnosis Gangguan Jiwa (PPDGJ) - III, kleptomania termasuk dalam kelompok gangguan kebiasaan dan impuls (F63).(1) Istilah kleptomania dikenalkan oleh psikiatri dari Perancis yang bernama Esquirol dan Mark pada abad ke-19.(2) Kleptomania memiliki dampak psikososial seperti penurunan kualitas hidup dan memiliki konsekuensi hukum.(3)

\section{TINJAUAN PUSTAKA}

\section{Epidemiologi}

Belum ada data pasti mengenai jumlah penderita kleptomania di Indonesia dan di dunia. Hal ini disebabkan karena seringkali penderita menyembunyikan kondisinya dan baru meminta pertolongan saat berurusan dengan hukum. Di Amerika Serikat, lembaga survey epidemiologi menunjukkan prevalensi pencurian sekitar 11,3\% dan diduga prevalensi kleptomania pada populasi pencuri tersebut sekitar 3,8 sampai 24\%.(4)
Sebuah studi yang dilakukan pada 791 siswa di Amerika Serikat menunjukkan terdapat 3 orang (0,38\%) yang memenuhi kriteria kleptomania.(5) Dari beberapa studi menunjukkan mayoritas penderita kleptomania adalah perempuan dengan perbandingan pelaku perempuan dan pria 3:1.(3)(6) Rata-rata usia pelaku adalah usia dewasa muda (30an), tetapi terdapat laporan onset prilaku mencuri mulai muncul pada usia paling muda 4 tahun dan paling tua 77 tahun.(7)

\section{Gejala klinis}

Kriteria diagnostik untuk kleptomania berdasarkan American Psychiatric Association Diagnostic and Statistical Manual of Mental Disorders diantaranya adalah prilaku mencuri barang berulang dimana penderita tidak mampu untuk mengendalikan keinginan tersebut. Barang yang dicuri biasanya tidak diperlukan oleh pasien dan bukan untuk dijual. Penderita merasakan peningkatan ketegangan sebelum melakukan aksinya dan merasakan kepuasan setelah berhasil melakukan aksinya. Tindakan mencuri bukan untuk mengekspresikan kemarahan atau balas dendam dan bukan merupakan respon dari halusinasi atau delusi.(1)(8) Walaupun ada perasaan kepuasan dan kesenangan setelah melakukan aksinya, penderita juga dapat mengalami perasaan bersalah atau depresi sesaat setelahnya.(3)

Kleptomania harus dibedakan dengan tindakan pencurian biasa. Pada kleptomania, pencurian tidak direncanakan sebelumnya dan bukan untuk memenuhi kebutuhan ekonomi yang

Vol. 6 No.1 Februari 2019 
kurang. Penderita kleptomania memilih mencuri pada akses yang mudah dan target yang acak, serta mencuri benda yang tidak berharga seperti pakaian, dan kaos kaki. Hal ini sangat berbeda dengan pencuri lain (yang bukan kleptomania) yang membuat strategi terlebih dahulu untuk mengambil barang yang berharga.(9) Ketika penderita ditanya alasan mengapa mencuri, maka penderita menjawab "saya tidak tahu". Penderita tidak dapat menjelaskan tujuan dan alasan mengapa ia melakukan pencurian. Ketika ditangkap dan ketahuan aksinya, penderita akan mengakui bahwa dia benar-benar melakukan pencurian. Penderita dengan kleptomania umumnya mempunyai hidup yang layak dan kondisi keuangan yang stabil. Bahkan beberapa adalah selebriti, mempunyai ijazah akademik yang tinggi dan status sosial yang tinggi.(10)

Kleptomania dapat berhubungan dengan gangguan kejiwaan lainnya seperti depresi,(11) kecanduan alcohol,(12) gangguan kecemasan (13) dan gangguan obsesif kompulsif (obsessive compulsive disorder / OCD).(14) Kleptomania memiliki kesamaan gejala dengan adiksi seperti adanya tekanan yang kuat sebelum keinginan tersebut dicapai, penurunan keinginan segera sesaat setelah aksi dilakukan, adanya jeda waktu (jam, hari atau minggu) terhadap munculnya keinginan melakukan aksi pencurian berulang, serta terdapat perasaan senang setelah melakukan aksinya.(15) Kleptomania juga dapat berkaitan dengan perubahan mood. Penderita kleptomania sering melaporkan gejala tersebut memburuk saat mereka mengalami depresi. Kleptomania dapat menjadi manifestasi hipomania atau mania pada penderita gangguan bipolar.(16)

Kleptomania harus dibedakan dari pencurian berulang tanpa manifestasi gangguan psikiatrik yang direncanakan dengan lebih hati-hati serta untuk mendapatkan keuntungan pribadi (Z03.2.), gangguan mental organik seperti gangguan ingatan yang menyebabkan penderita lupa membayar barang belanjaan (F00 - F09) serta pencurian yang disebabkan gangguan depresi (F30 - F33).

Terdapat beberapa alat bantu untuk penegakkan diagnosis kleptomania diantaranya adalah Yale Brown Obsessive Compulsive Scale Modified for Kleptomania (K-YBOCS) dan Kleptomania Symptom Asessment Scale (K-SAS). K-YBOSC merupakan alat ukur keparahan gejala kleptomania selama 7 hari terakhir yang terdiri dari 10 poin mengenai pemikiran dan prilaku penderita. Setiap poin memiliki skala $0-4$ yang dinilai oleh klinisi.(17) Sedangkan K-SAS memiliki 11 poin penilaian yang dapat dinilai oleh pasien sendiri yang terdiri dari keinginan, pemikiran dan prilaku pasien selama 7 hari terakhir.(3)

\section{Patofisiologi}

Penyebab terjadinya kleptomania masih belum dipahami sampai saat ini. Terdapat beberapa teori mengenai terjadinya kleptomania diantaranya adalah teori psikoanalitik dan teori psikoseksual. Teori psikoanalitik menghubungkan kleptomania dengan trauma masa lalu dan mencuri merupakan simbol kehilangan masa kecil.(18) Teori psikoseksual menghubungkan antara

Vol. 6 No.1 Februari 2019 
kleptomania dengan represi dan supresi seksual.(18)

Beberapa hipotesis terjadinya kleptomania yang berkaitan dengan neurobiologis diantaranya adalah penurunan integritas white matter pada regio frontal inferior sehingga mengganggu jalur regio limbik ke thalamus dan regio prefrontal, gangguan transporter serotonin (19) dan kerusakan sirkuit orbitofronto-subkortikal (20). Terdapat dua laporan kasus yang menunjukkan terjadinya gejala kleptomania setelah trauma kepala yang diduga disebabkan oleh defisit perfusi lobus temporal.(21)

\section{Terapi Farmakologi}

\section{Selective serotonin reuptake inhibitors (SSRI)}

Selective serotonin reuptake inbibitors (SSRI) merupakan golongan antidepresan yang bekerja dengan meningkatkan level serotonin di otak. Serotonin merupakan neurotransmitter yang berperan dalam memperbaiki mood, meningkatkan nafsu makan dan membantu regulasi siklus sirkadian tubuh. Obat golongan SSRI meningkatkan level serotonin di tubuh dengan cara mencegah sel saraf melakukan reuptake serotonin. Obat golongan SSRI yang pernah digunakan untuk terapi tunggal kleptomania diantaranya adalah fluoxetine, fluvoxamine dan paroxetine.(22) Walaupun begitu masih belum ada studi terkontrol mengenai efektivitas obat ini. Terdapat beberapa laporan kasus yang menunjukkan fluoxetine gagal mengurangi gejala kleptomania, bahkan gejala kleptomania dilaporkan justru meningkat pada tiga pasien yang diterapi dengan obat golongan SSRI.(23)

\section{Naltrexon}

Naltrexon merupakan terapi medikasi terhadap adiksi alcohol yang telah disetujui oleh badan pengawasan obat dan makanan Amerika Serikat (FDA). Naltrexon bekerja mengurangi kecanduan alkohol dengan cara menghambat pelepasan dopamine pusat yang dimediasi oleh opioid. Obat dapat diberikan secara per oral sekali sehari dengan dosis $50 \mathrm{mg} /$ hari maupun dengan injeksi sebulan sekali (rentang dosis 50 - 150 mg).(24) Pemberian Naltrexon dapat mengurangi keinginan untuk mengkonsumsi alkohol. Karena kleptomania memiliki kesamaan gejala dengan adiksi alkohol, maka diduga Naltroxon juga dapat mengurangi kecanduan penderita terhadap mencuri. Sebuah studi menunjukkan mengurangi keinginan mencuri pada 23 penderita kleptomania secara signifikan. Obat ini juga ditoleransi baik oleh penderita dengan dosis efektif rata-rata adalah $116,7 \mathrm{mg} /$ hari.(25)

\section{Psikoterapi}

Selain terapi obat-obatan, penderita kleptomania harus diterapi dengan psikoterapi. Dokter psikiatri harus mengetahui penyebab utama penderita melakukan hal tersebut dan membantu penderita untuk melepaskan stresnya. Beberapa psikoterapi yang banyak dilakukan untuk penderita kleptomania adalah Cognitive Behavioral Therapy (CBT), psikoterapi kognitif, desensitisasi sistemik dan terapi aversi. Psikoterapi ini bertujuan untuk mengubah persepsi penderita terhadap tindakan mencuri dan mengalihkan minat ke hal lain. Ketika penderita mengalami keinginan untuk mencuri, maka stimulus akan diberikan untuk

Vol. 6 No.1 Februari 2019 
menginduksi emosi yang tidak menyenangkan terhadap tindakan tersebut sehingga keinginan mencuri penderita akan menurun. Penderita disarankan untuk mencatat semua aktivitas seharihari dalam buku harian sebagai evaluasi mandiri.(10) Selain psikoterapi dan farmakoterapi, keterlibatan keluarga juga sangat penting untuk mengoptimalkan terapi pada penderita kleptomania sehingga tercapai keberhasilan terapi.

\section{KESIMPULAN}

Dari uraian yang sudah dijelaskan di atas, dapat disimpulkan bahwa kleptomania (curi patologis) merupakan gangguan pada psikologis yang ditandai dengan keinginan untuk mencuri yang tidak bisa dikendalikan. Penderita kleptomania mencuri barang yang tidak penting seperti baju, dan kaos kaki karena tujuan dari pencurian tersebut bukanlah untuk balas dendam maupun memenuhi kebutuhan ekonomi, melainkan untuk memenuhi kepuasan dirinya sendiri. Ketika ditanya alasan mengapa melakukan tindakan tersebut, pasien akan kebingungan karena tidak mengetahui alasannya. Pencurian tersebut terus menerus dilakukan karena sensasi ketegangan yang dapat menimbulkan kepuasan tersendiri untuk pasien. Tata laksana untuk pasien kleptomania terbagi menjadi 2 yaitu psikofarmakologi dan psikoterapi. Terapi psikofarmakologi meliputi Selective serotonin reuptake inhibitors (SSRI) dan Naltrexon. Psikoterapi sendiri mempunyai tujuan untuk mengubah persepsi pendertita terhadap tindakan mencuri dan mengarahkannya kepada hal lain yang lebih positif.

\section{DAFTAR PUSTAKA}

1. Muslim R. Buku saku diagnosis gangguan jiwa Rujukan Ringkas dari PPDGJ-III dan DSM-5. Jakarta: Bagian Ilmu Kedokteran Jiwa FK Unika Atma Jaya; 2001.

2. MJ G. Kleptomania: making sense of the nonsensical. Am J Psychiatry. 1991;148:986-96.

3. Grant JE KS. Clinical characteristics and associated psychopathology in 22 patients with kleptomania. Compr Psychiatry.

2002;43::378-384.

4. Blanco C, Grant J, Petry NM, Simpson HB, Alegria A, Liu SM HD. Prevalence and correlates of shoplifting in the United States: results from the National Epidemiologic Survey on Alcohol and Related Conditions (NESARC). Am J Psychiatry. 2008;165(7):905-13.

5. Odlaug BL GJ. Impulse-control disorders in a college sample: results from the selfadministered Minnesota Impulse Disorders Interview (MIDI). Prim Care Companion J Clin Psychiatry. 2010;12(2).

6. Aboujaoude E, Gamel N KL. Overview of kleptomania and phenomenological description of 40 patients. J Clin Psychiatry. 2004;6:224-47.

7. J P. Childhood kleptomania: Two clinical case studies with implications for further research. Psychol Educ - An Interdiscip J. 2002;39:19-21.

8. American Psychiatric Association. Vol. 6 No.1 Februari 2019 
Diagnostic and Statistical Manual of Mental Disorders. fourth, Te. Washington DC: American Psychiatric Association; 2000.

9. S Urso, G.Bersani, P.Roma, R.Rinaldi. Changes in impulse control disorder features in a present kleptomania patient and importance of rational treatment strategy on social dangerousness: a case report. J Psychopathol. 2018;24:31-6.

10. Zhang Z, Huang F, Liu D. Kleptomania: Recent Advances in Symptoms, Etiology and Treatment. Curr Med Sci. 2018;38(5):937-40.

11. Lejoyeux M, Arbaretaz M, McLoughlin M AJ. Impulse control disorders and depression. J Nerv Ment Dis. 2002;190:310-4.

12. Lejoyeux M, Feuche N, Loi S, Solomon J AJ. Study of impulse-control disorders among alcohol-dependent patients. J Clin Psychiatry. 1999;60:302-305.

13. McElroy SL, Pope HG, Jr, Hudson JI et al. Kleptomania: a report of 20 cases. Am J Psychiatry. 1991;148:652-7.

14. Presta S, Marazziti D, Dell'Osso L, Pfanner C P, S CG. Kleptomania: Clinical features and comorbidity in an Italian sample. Compr Psychiatry. 2002;43:7-12.

15. I M. Behavioural (non-chemical) addictions. Br J Addict. 1990;85:13891394.

16. McElroy SL, Pope HG, Hudson JI, Keck PE, Jr. W, KL. Kleptomania: A report of
20 cases. Am J Psychiatry. 1991;148:652657.

17. Kim SW, Dysken MW, Pheley AM HK. The Yale-Brown Obsessive-Compulsive Scale: measure of internal consistency. Psychiatry Res. 1994;51:203-211.

18. Sadock BJ, Kaplan HI SV. Synopsis of Psychiatry. Tenth. Philadelphia, PA: Lippincott Williams \& Wilkins; 2007.

19. Marazziti D, Mungai F, Giannotti D et al. Kleptomania in impulse control disorders, obsessive-compulsive disorder, and bipolar spectrum disorder: Clinical and therapeutic implications. Curr Psychiatry Rep. 2003;5:36-40.

20. Nyffeler T RM. Kleptomania in a patient with a right frontolimbic lesion.

Neuropsychiatr Neuropsychol Behav Neurol. 2001;14:73-76.

21. Aizer A, Lowengrub K DP. Kleptomania after head trauma: Two case reports and combination treatment strategies. Clin Neuropharmacol. 2004;27:211- 215.

22. Grant JE PM. Impulse control disorders: Clinical characteristics and pharmacological management. Ann Clin Psychiatry. 2004;16:27-34.

23. Kindler S, Dannon P, Iancu I, Horesh N KM. Emergence of kleptomania during treatment for depression with serotonin selective reuptake inhibitors. Clin Neuropharmacol. 1997;20:126-129.

24. Shantrel S. Canidate, Giselle D. Carnaby, Christa L. Cook RLC. A Systematic Vol. 6 No.1 Februari 2019 
37 Yelvi Levani et al

Review of Naltrexone for Attenuating

Alcohol Consumption in Women with

Alcohol Use Disorders (AUD). Alcohol

Clin Exp Res. 2017;41(3):466-72.

25. Grant JE, Kim SW, Odlaug BL. A double- blind, placebo-controlled study of the opiate antagonist, naltrexone, in the treatment of kleptomania. Biol Psychiatry. 2009;65(7):600-6.

Vol. 6 No.1 Februari 2019 